Article

\title{
How Does ICT Expansion Drive "Smart" Urban Growth? A Case Study of Nanjing, China
}

\author{
Zipan Cai ${ }^{1}$, Vladimir Cvetkovic ${ }^{1}$ and Jessica Page ${ }^{2, *}$ \\ ${ }^{1}$ Department of Sustainable Development, Environmental Science and Engineering, KTH Royal Institute of Technology, \\ 10044 Stockholm, Sweden; E-Mails: zipan@kth.se (Z.C.), vdc@kth.se (V.C.) \\ 2 Department of Physical Geography, Stockholm University, 10691 Stockholm, Sweden; E-Mail: jessica.page@natgeo.su.se \\ * Corresponding author
}

Submitted: 15 October 2019 | Accepted: 10 February 2020 | Published: 13 March 2020

\begin{abstract}
In the context of accelerated urbanization, socioeconomic development, and population growth, as well as the rapid advancement of information and communication technology (ICT), urban land is rapidly expanding worldwide. Unplanned urban growth has led to the low utilization efficiency of land resources. Also, ecological and agricultural lands are continuously sacrificed for urban construction, which in the long-term may severely impact the health of citizens in cities. A thorough understanding of the mechanisms and driving forces of a city's urban land use changes, including the influence of ICT development, is therefore crucial to the formation of optimal and feasible urban planning in the new era. Taking Nanjing as a study case, this article attempts to explore the measurable "smart" driving indicators of urban land use change and analyze the tapestry of the relationship between these and urban land use change. Different from the traditional linear regression analysis method of driving force of urban land use change, this study focuses on the interaction relationship and the underlying causal relationship among various "smart" driving factors, so it adopts a fuzzy statistical method, namely the grey relational analysis (GRA). Through the integration of literature research and known effective data, five categories of "smart" indicators have been taken as the primary driving factors: industry and economy, transportation, humanities and science, ICT systems, and environmental management. The results show that these indicators have different impacts on driving urban built-up land growth. Accordingly, optimization possibilities and recommendations for development strategies are proposed to realize a "smarter" development direction in Nanjing. This article confirms the effectiveness of GRA for studies on the driving mechanisms of urban land use change and provides a theoretical basis for the development goals of a smart city.
\end{abstract}

\section{Keywords}

grey relational analysis; ICT; land use change; smart city; urban planning; urbanization

\section{Issue}

This article is part of the issue "Urban Planning and the Smart City: Projects, Practices and Politics" edited by Andrew Karvonen (KTH Royal Institute of Technology, Sweden), Matthew Cook (Open University, UK) and Håvard Haarstad (University of Bergen, Norway).

(C) 2020 by the authors; licensee Cogitatio (Lisbon, Portugal). This article is licensed under a Creative Commons Attribution 4.0 International License (CC BY).

\section{Introduction}

The world is currently undergoing tremendous change, and the significant progress in information and communication technology (ICT) increasingly convinces us that the era of smart city has already arrived (Karvonen,
Cugurullo, \& Caprotti, 2018). The upgrading of traditional industries driven by digitalization, especially in the manufacturing, commerce, and service industries, has brought about structural change (Loo \& Wang, 2017). The ubiquitous network of information infrastructure, as well as the services it provides, have redefined the con- 
cept of location, while the elements of a city that are affected by the information infrastructure have reshaped the form, space, and texture of a city as a whole (Bibri \& Krogstie, 2017; Chourabi et al., 2012; Graham, 2002). The concept of a smart city aims at the integration of ICT and other new technologies and services to promote smart urban growth; this concept has been placed on the development agenda by policymakers around the world since it was first proposed in the early 21st century (Neirotti, de Marco, Cagliano, Mangano, \& Scorrano, 2014). However, due to the different characteristics and needs of urban development in different countries and regions, there is no uniform definition and implementation route for a smart city, for example, some cities focus on "smartness" through electronic intelligence, while others might focus instead on promoting high-tech industries (Albino, Berardi, \& Dangelico, 2015). Empirical research shows that the evolution and development of a smart city are highly dependent on its local socioeconomic factors, including industry, economy, transportation, energy, environment, infrastructure, people, and governance (Makushkin, Kirillov, Novikov, Shaizhanov, \& Seidina, 2016). Although the international debate on the development of smart cities is still ongoing, one fact has been recognized as universal-the application of ICT in all areas of a city can help to improve the efficiency of resource utilization, urban management, and services, and ultimately to improve the citizens' living quality (Albino et al., 2015; Allwinkle \& Cruickshank, 2011; Batty et al., 2012). As highlighted by today's smart city advocates, ICT will eventually bring together the various service functions of a city into a diverse, complex, interconnected, and manageable system (Cocchia, 2014; Ergazakis, Metaxiotis, \& Psarras, 2004). In such a context, how should urban planners incorporate ICT and the concept of a smart city into their development strategies, given the unknown impact of ICT?

The advancement of ICT presents enormous challenges in medium- and long-term urban land use planning, as it improves the information interaction nodes, modes, and systems of cities from different scales, such as urban infrastructure, building, public space, and environmental elements (Hernández-Muñoz et al., 2011). ICT also has an interwoven influence on travel behavior, reflected in the guiding role of ICT in specific travel decisions, such as population mobility activities, travel means and supplies, and citizens' lifestyle and location decisions (Mokhtarian \& Tal, 2013). Therefore, small decisions about ICT development may have a significant impact on the size of the city, especially in terms of urban land expansion (Maeng \& Nedovic-Budic, 2010). Urban planners need to be aware of the potential impacts of ICT development of urban land use so that they can make informed, forward-looking planning decisions. If today's urban land use can be understood as the combination of land resource utilization and urbanization, then the concept of a smart city can be understood as the integration of digitalization and urbanization (Anthopoulos
\& Vakali, 2012). Studying urban land use changes from the perspective of smart city development means an indirect integration between digitalization and land use, which aims to help us explore how the development of ICT promotes the evolution of urban land use. Therefore, as the main driving force for the development of information society, ICT construction and management should be considered as a new aspect of urban planning.

Recent studies have attempted to systematically analyze the link between urban land use changes and the effect of ICT development, with the aim of helping urban planners and policy makers to understand the controllability of urban expansion (Chen, Chang, Karacsonyi, \& Zhang, 2014; Maeng \& Nedovic-Budic, 2007). Most of these studies indicate that it is challenging to recognize the impact of complex and diverse changes in urban space and land use generated by ICT development due to the ambiguous linkages. Meanwhile, comprehensive studies have also pointed out that various aspects of urban development that are directly affected by ICT development include urban transportation systems, industry and economy, science and technology, and information systems (Cohen-Blankshtain \& Rotem-Mindali, 2016; Eggleston, Jensen, \& Zeckhauser, 2002; Maeng \& Nedovic-Budic, 2010). These aspects have also been identified as important factors driving urban land growth in traditional land use driving force studies (Braimoh \& Onishi, 2007; Parcerisas et al., 2012; Serra, Pons, \& Saurí, 2008). However, with the emergence of the information era, the traditional factors driving urban land use changes have also been largely affected. Therefore, in order to help urban planners and policy-makers better implement urban "smart" development strategies, it is necessary to study and identify those land use drivers affected by ICT and their potential impact on urban land growth.

To fill the knowledge gap, we need to understand how local use and management of ICT take place across different levels of implementation including local, regional, and national strategies (Firmino, 2005). This article quantitatively analyzes the driving role of various smart city factors in urban development and explores the relationship between such factors and urban land use changes, in order to provide new insight relevant for future land development and urban planning. Since research on smart cities involves multiple socioeconomic aspects which are tightly connected, there is no uniform unit quantification standard for the various driving factors of land use changes. Besides, the construction of a smart city is led by the local government and the nature of every smart city is unique and highly context-dependent. Consequently, this article begins with the development strategy analysis of a case study city-Nanjing. Together with similar studies in the past, this article attempts to qualitatively identify the driving factors of smart city development with influential characteristics.

Due to the limitation of the publicly available data, it is almost impossible to fully take all driving factors into ac- 
count. This article therefore uses the grey relational analysis (GRA) method to reduce the correlation error caused by the limitation in sample size and the uncertainty in the trend. Compared with the commonly used mathematical statistics methods, such as the analysis of variance, regression analysis, and main component analysis, the GRA method has advantages in generating consistent results of quantitative and qualitative phenomena. It is also widely applicable to small and irregular samples, using relatively simple calculations to reveal the dynamic characteristics of ICT-driven development (Kuo, Yang, \& Huang, 2008).

The overall goal of this study is to discover what the ICT-led driving factors of urban land use change are in the context of smart city development in the studied city of Nanjing. Additionally, the purpose is to learn how these are associated with Nanjing's urban built-up land expansion. The specific objectives are to:

- Analyze the driving factors and driving mechanisms of urban land use change, applied to Nanjing;

- Explore the ICT-led "smart" driving factors of urban land use change using city development indicators applied to Nanjing;

- Implement the GRA method to analyze how "smart" driving factors correlate with urban land use change, applied to the city of Nanjing.
This article is organized into five sections. Section 2 studies the primary driving mechanism of urban land use change, applied to the city of Nanjing. Section 3 implements a quantitative correlation analysis on "smart" land use change drivers. Section 4 presents an empirical analysis followed by discussions on the data processing results. Section 5 summarizes the main findings and future research directions.

\section{Study Area and Driving Factors}

\subsection{Study Area}

Nanjing is a Chinese city with rich historical and cultural heritage, natural landscape and environmental resources, and modern landmark buildings. The city has long been an economic, political, cultural, education, and transportation center of southern China. Today, Nanjing is the capital of one of the wealthiest provinces of China, Jiangsu. As shown in Figure 1, Nanjing is located along the lower reaches of the Yangtze River in the southwest area of Jiangsu province. Today's Nanjing still adheres to the strategy of an open and innovative city-region. In 2006, Nanjing responded to the first call of the state in the new era and proposed a smart Nanjing strategy, "Build Smart City, Guide Future Development," which intended to dig deep into the advantages of urban resources endowment. Shortly after this, in 2008, the local govern-
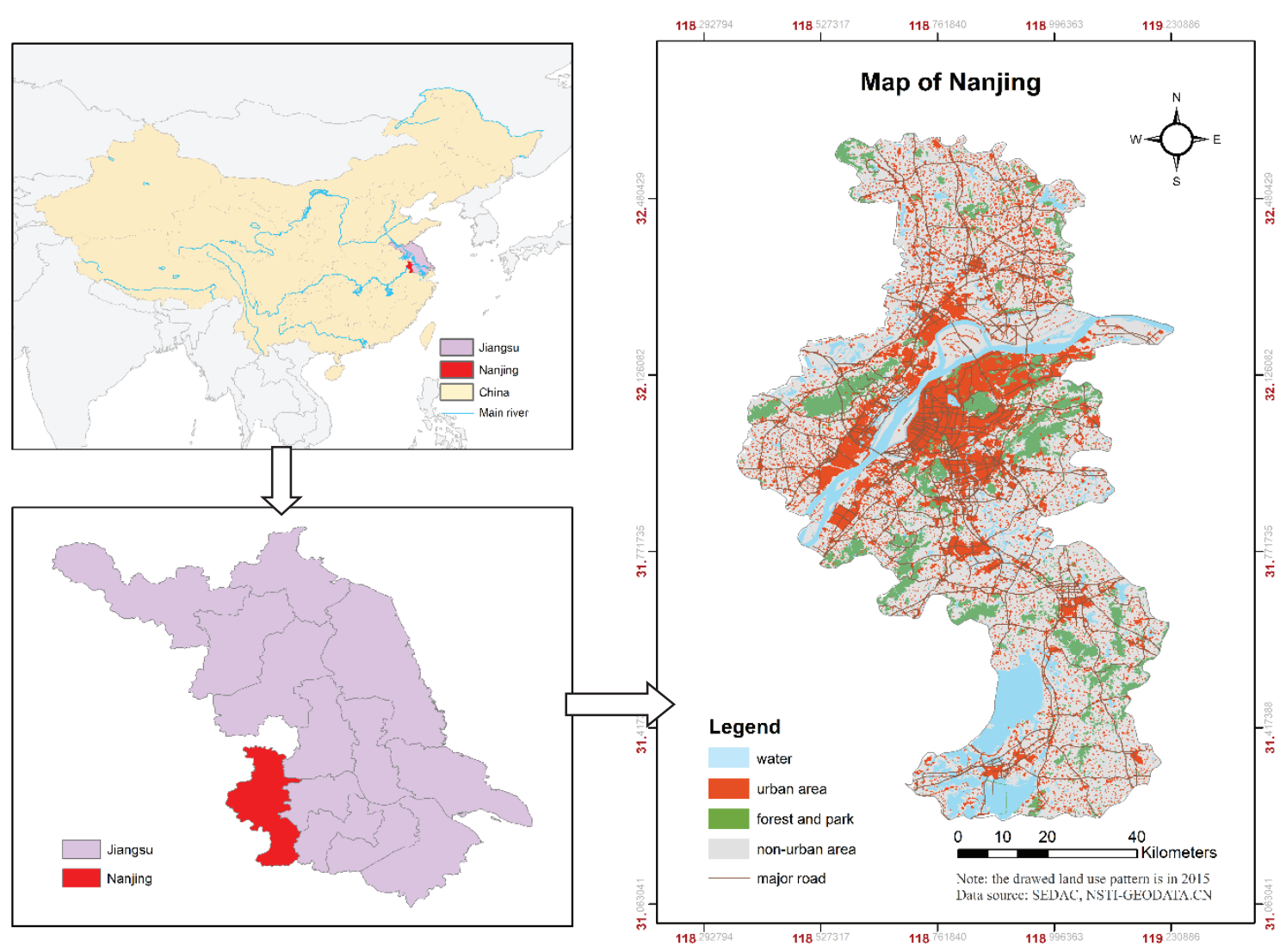

Figure 1. Map of Nanjing. Source: Authors. 
ment included all the significant planning details of the smart city construction strategy into their 12th five-year urban development plan (Hu, Yan, \& Wang, 2010). In the following years, due to the ongoing development of ICT, the internet of things, cloud computing, and other new technologies, Nanjing accelerated the construction of the smart city in the direction of the information industry, aiming to improve the level of social information and living standards of citizens. In 2013, Nanjing launched 46 smart city projects with a raised investment of 30.3 billion CNY (Tan-Mullins, Cheshmehzangi, Chien, \& Xie, 2017). Most of these projects utilized ICT to improve citizens' social engagement with the city administrators, enhance public transportation, create enterprise opportunities, secure public safety, and sustain urban development. Designated as the pioneer of the smart city in China, smart Nanjing has made breakthroughs in areas including organizational establishment, data openness, civil service upgrade, and institutional innovation. The determination of the city in the strategic planning for the development of a smart city has made it a reality for the huge amount of capital investment in accelerating digitalization and urbanization. At the same time, the population is surging and the city is expanding significantly; all these characteristics make Nanjing an interesting case for this study.

\subsection{Driving Factors}

Urban land use changes take place under the joint influence of physical geographical factors and socioeconomic factors (Wang \& Zhang, 2001). However, due to the different local characteristics and policies of different cities, its impacts vary greatly from place to place (Lambin et al.,
2001). Thus, it is necessary to comprehensively analyze the complex factors such as the current development characteristics and policy status quo of the city. First, from the perspective of physical geographical factors, urban land use changes are usually restricted by local topography, soil, climate, biology, and so on. However, Nanjing is a city with rich natural resources, fertile soil, mild climate, and adequate water resources, all of which provide superior natural conditions for people to transform land use types with few restrictions (Platt, 2004). Such kinds of factors usually have minimal impact on urban land use changes in non-long-term studies. Besides, most studies have confirmed that socioeconomic factors are the most important driving force for the constant change of urban land use (Han, Hayashi, Cao, \& Imura, 2009; Li, Zhou, \& Ouyang, 2013). These factors usually include population, transportation, culture, industry, economy, technology, infrastructure, and more.

Because of the diversity and abstract evolution of socioeconomic factors under digitalization, the extended construction factors of smart cities have complex and profound effects on urban land use change. From the perspective of the driving mechanism, the construction of the smart city in Nanjing has a driving influence on the primary form of urban land use layout and the distribution of urban functional areas. Figure 2 shows a conceptual model that indicates the occurrence and effect of urban land use change driving mechanisms, as applied to Nanjing. Due to the different local conditions and goals of smart city development in different regions, the impact on urban land use change is also disparate. Therefore, this concept-driven model is only applicable to the specific city studied here.

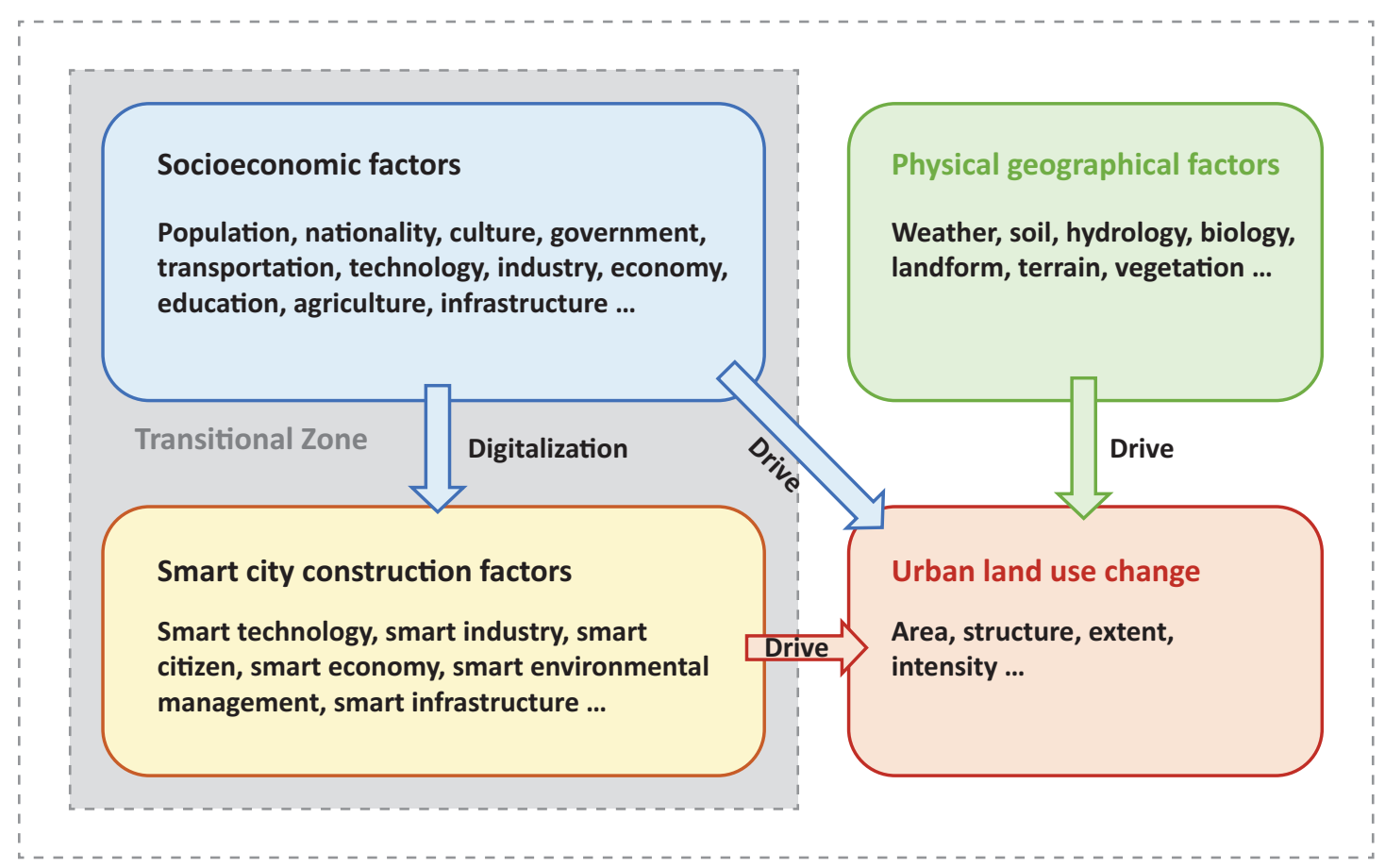

Figure 2. Conceptual model of urban land use change driving mechanism in Nanjing. 


\section{Quantitative Analysis of "Smart" Driving Forces}

\subsection{What Are the "Smart" Driving Forces?}

The driving factors of a smart city are closely related to its development indicators, and some valuable information can be found in the relevant literature. Lea (2017) divides the factors influencing the development of smart cities into three categories: the technology aspects (i.e., the progress of technology itself), human aspects (such as lifestyle, education, and social aspects), and institutional aspects (such as urban planning and governance). All of these aspects are thoroughly interlinked and influence each other, and together they influence how the progression of technology affects the development of the urban environment. The progression of technology influences both how people behave within the urban environment and the possibilities for development using smart technologies. These influences, when parsed through the planning and governance institutions, eventually determine how the smart city will develop. Lombardi, Giordano, Farouh, and Yousef (2012) refer to the triple-helix of technological and smart city development as universities, government, and industry. These three parties, together with civil society, determine how technology will develop and influence the development of smart cities. In evaluating their influences on the city and the smart city's performance, they di- vide the aspects defining smart cities into five clusters, namely smart governance, smart economy, smart human capital, smart living, and smart environment.

Similarly, Giffinger, Fertner, Kramar, and Meijers (2007) create a smart city assessment approach for European smart cities, which evaluates the smart city system according to six indicators: smart economy, smart transportation, smart environment, smart residents, smart life, and smart management. There are many commonalities among these assessment methodologies for smart cities. For example, the evaluation system of smart city development is mainly based on the primary evaluation indicator of social and economic development. Therefore, we need to take into account some similarities between the main direction of the regional smart city development strategy and the evaluation system of the smart city in other studies. Based on the formulation and revision of Nanjing's smart city development strategy over the years, as well as the accessibility of the most relevant data, this study finally selects the following smart city development indicators as shown in Table 1. It can be noted the characteristics of the primary indicators are that they are all driving factors of land use change led by socioeconomic factors as discussed in Section 2.2. However, the focus of this study is still the indicator with the main representative characteristics of these aspects after being affected by ICT development. Thus, we have added sub-indicators to the five primary

Table 1. Nanjing smart city development indicators.

\begin{tabular}{|c|c|c|}
\hline Primary indicator & Secondary indicator & Secondary indicator variable (units) \\
\hline \multirow{3}{*}{$\begin{array}{l}\text { Smart industry and } \\
\text { economy }\end{array}$} & Economic strength & X1: GDP per capita (CNY) \\
\hline & Industrial structure & $\begin{array}{l}\mathrm{X} 2 \text { : The fixed social assets investment amount of the } \\
\text { tertiary industry }(1,000,000 \mathrm{CNY})\end{array}$ \\
\hline & Smart industry profitability & X3: Added value of tertiary industry $(1,000,000 \mathrm{CNY})$ \\
\hline \multirow[t]{3}{*}{ Smart transportation } & Urban space layout & X4: The area of roads (hectare) \\
\hline & Public transportation resources & $\begin{array}{l}\text { X5: The actual number of buses in operation at the } \\
\text { end of the year (units) }\end{array}$ \\
\hline & New means of public transportation & $\begin{array}{l}\text { X6: The number of rail transit vehicles in operation } \\
\text { at the end of the year (units) }\end{array}$ \\
\hline \multirow{3}{*}{$\begin{array}{l}\text { Smart humanities } \\
\text { and science }\end{array}$} & Education expenditure & X7: Education expenditure per capita (CNY) \\
\hline & Population structure and quality & $\begin{array}{l}\text { X8: The proportion of the population with higher } \\
\text { education over the age of } 25(\%)\end{array}$ \\
\hline & Human resources & $\begin{array}{l}\text { X9: The proportion of employees in the ICT industry } \\
\text { in the whole society (\%) }\end{array}$ \\
\hline \multirow[t]{3}{*}{ Smart ICT system } & Telephone communication environment & X10: Number of mobile phone users $(10,000)$ \\
\hline & Urban hardware facilities & X11: Number of inhouse fiber optic networks $(10,000)$ \\
\hline & Logistics system & X12: Quantity of express delivery $(10,000)$ \\
\hline \multirow{3}{*}{$\begin{array}{l}\text { Smart environment } \\
\text { management }\end{array}$} & Waste handling capacity & X13: Treatment rate of domestic sewage (\%) \\
\hline & Urban green environment & X14: Green coverage in built-up areas (\%) \\
\hline & Urban ecological service & X15: The area of parks (hectare) \\
\hline
\end{tabular}

Note: Units of some selected variables have been adjusted to ensure unit consistency and ease of calculation. 
indicators after the "smart" upgrade, making them different from the traditional land use driver indicators. Under each primary indicator except the smart ICT system, not only a representative traditional indicator (refer to $\mathrm{X} 1$, $\mathrm{X} 4, \mathrm{X} 7, \mathrm{X} 14$, and $\mathrm{X} 15$ ) will be considered, but also at least one "smart" secondary indicator will be included. Such diversified indicators will be included in the system to ensure that the final comparison result may produce more valuable information.

\subsection{Data Collection}

This study used the annual statistics of Nanjing from both the Statistical Yearbook of Nanjing and the Statistical Yearbook on Urban and Rural Construction. Based on the timing of Nanjing smart city construction and the availability of data, this study selected the corresponding variables of Nanjing smart city construction indicators from 2008 to 2018 as the research data, as shown in Table 1 in Supplementary File 1 . In addition, we use the proportion of built-up area to urban area as the reference data, as shown in Table 2 in Supplementary File 1.

\section{3. $G R A$}

\subsubsection{Theory}

GRA was developed by Deng (1982) and has been applied in various research fields in recent years. The theory of GRA is to use certain mathematical calculations to measure the degree of association between variables according to the similarity and difference of the dynamic development changes among these variables based on cybernetics, information theory, and so on, so as to reveal the characteristics of dynamic association across different objects (Deng, 1989). As a multi-factor statistical analysis method, its largest advantage in the study of the drivers of urban land use change is the "grey" relationship system build-up while the interaction strength is unknown between the main factors and reference factors (Yang et al., 2008). This is in line with the research status of "smart" driving factors with unclear causal relationships and incomplete coverage. According to cybernetic conventions, the color from white to black represents the amount of known system information, and the grey is between the two-representing that we only have limited understanding of the internal structure of the system. Similarly, the value of the calculated grey relational coefficient from low to high (value range from 0 to 1 ) also means that the correlation between measurement factors and reference factors varies from low to high.

\subsubsection{Data Normalization Processing}

The core theory of grey correlation degree is to calculate the degree of relation between different variables. However, because there are different measurement units among statistical data, there are differences in dimensions and quantities. Different dimensions and orders of magnitude are difficult for comparison and analysis, which may lead to outcome errors and wrong conclusions. Therefore, dimensionless processing is required in this step for the original data. Typically, the general dimensionless processing mode used " $0-1$ normalization," as:

$$
y_{i j}=\frac{x_{i j}-\min \left(x_{i j}\right)}{\max \left(x_{i j}\right)-\min \left(x_{i j}\right)}
$$

Here, $y_{i j}$ is the normalized data of the original data $x_{i j}$; $i$ and $j$ indicate the $i$ 'th indicator variable and the year of $j$ in the collected research data. The results of normalization processing are shown in Table 1 in Supplementary File 2.

\subsubsection{Grey Correlation Coefficient Modeling}

In this section, we code in R and use RStudio software to transform and modeling the research data. $R$ is an open-source programming language that provides complete support for data statistical processing and research while R Studio is the support system for R with an integrated development environment (Campbell, 2019).

Suppose the reference sequence after normalization is:

$$
\left\{y_{0}(t)\right\}=\left\{y_{01}, y_{02}, y_{03}, \ldots, y_{0 t}\right\}
$$

The sequences that are compared in correlation with the reference sequence are:

$$
\left\{y_{1}(t), y_{2}(t), \ldots, y_{p}(t)\right\}=\left\{\begin{array}{cccc}
y_{11} & y_{12} & \ldots & y_{1 n} \\
y_{21} & y_{22} & \ldots & y_{2 n} \\
\ldots & \ldots & \ldots & \ldots \\
y_{p 1} & y_{p 2} & \cdots & y_{p m}
\end{array}\right\}
$$

Here, $n$ represents the data length of the sequence. If we calculate the difference of $k$ th $(k=[1,2,3, \ldots, p])$ value in the same period between the comparison sequence and the reference sequence, the absolute value of the difference is (while $t=1,2,3, \ldots$ n.):

$$
\Delta_{0 k}(t)=\left|y_{0}(t) y_{k}(t)\right|
$$

Then we can retrieve the maximum and minimum values from the absolute difference series, which are denoted as $(\max )$ and $(\min )$ respectively. The $(\max )$ and $(\min )$ are further used for grey correlation coefficient calculation:

$$
\gamma_{0 k}(t)=\frac{\Delta(\min )+\rho \Delta(\max )}{\Delta_{0 k}(t)+\rho \Delta(\max )}
$$

Here, $\rho$ is the distinguishing coefficient, whose function is to weaken the influence of the distortion of correlation coefficient due to the large $\Delta$ (max). Typically, $\rho$ is assumed to be 0.5 .

Since the general correlation degree between the comparison sequences and the reference sequences is calculated by $n$ correlation coefficient, it is necessary to centralize the correlation information. Generally, the mean value of correlation degree of $p$ comparison se- 
quences and reference sequences in each period is used to quantitatively reflect the overall correlation as follows:

$$
r_{0 k}=\frac{1}{n} \sum_{i=1}^{n} \gamma_{0 k}(t)
$$

\section{Results and Discussions}

The detailed calculation results of the grey correlation coefficient modeling are shown in Table 2 in Supplementary File 2. A higher grey correlation degree means a stronger correlation between the comparison sequence and the reference sequence. For an empirical view, when the distinguishing coefficient is set to 0.5 , a correlation degree greater than 0.6 indicates a high correlation (Deng, 1989). As can be seen from the summarized results of grey correlation degree as shown in Table 2, the distribution of the correlation degree value of each "smart" driving factor is spread between 0.598 and 0.956 . It indicates that Nanjing's "smart" drivers do have a correlation with local urban land use change, and it is probable that they drive urban land expansion to various extents.

The results of the correlation degree of the primary indicator of smart city development are summarized in Figure 3, which shows its distribution is from 0.721 to 0.922 . It shows that all primary indicators have varying correlations with urban land expansion; the specific analysis for the indicators follows.

It can be seen from the primary indicators that the correlation between smart industry and economy and the change of urban land utilization ratio is the highest of all (0.922). Furthermore, the correlation values of all the three secondary indicators are above 0.9 , indicating that smart industrial and economic development has a significant impact on the change of urban land use in Nanjing. Per capita GDP, which is not only a factor that drives the change of urban land use in the traditional sense but also a basic indicator measuring the economic development of a smart city, can reflect a city's economic strength, as well as its transformation and innovation capabilities. Since the implementation of the informatization strategy in Nanjing, the dynamic effect brought about by innovative industrial transformation has greatly promoted the demand for urban land. For example, the development of new districts and the reconstruction of shanty towns have both directly affected the development extent and intensity of urban land use in Nanjing. The growth of the tertiary industry in terms of investment and added value year-by-year reveals the improvement and evolution of the urban industrial structure from traditional manufacturing to circulation and service industries. Meanwhile, as the informatization process speeds up, the tertiary industry has also had a technological transformation and begun to add more value, resulting in the expansion and transformation of urban land use in a manner which is both more intensive and efficient.

The grey correlation of smart transportation is also 0.922 , which ties with the indicator of smart industrial economy as the factor with the highest correlation, suggesting that the development of transportation is another factor closely related to the change of urban land use in Nanjing. Specifically, the increase of total road area shows that the urban spatial scale has become less constrained by the time scale, which to some extent reflects

Table 2. Grey correlation degree results for "smart" driving factors.

\begin{tabular}{|c|c|c|c|}
\hline Primary indicator & R degree & Secondary indicator variable & R degree \\
\hline \multirow{3}{*}{$\begin{array}{l}\text { Smart industry and } \\
\text { economy }\end{array}$} & \multirow[t]{3}{*}{0.922} & X1: GDP per capita & 0.948 \\
\hline & & X2: The fixed social assets investment amount of the tertiary industry & 0.912 \\
\hline & & X3: Added value of tertiary industry & 0.907 \\
\hline \multirow[t]{3}{*}{ Smart transportation } & \multirow[t]{3}{*}{0.922} & X4: The area of roads & 0.956 \\
\hline & & X5: The actual number of buses in operation at the end of the year & 0.914 \\
\hline & & X6: The number of rail transit vehicles in operation at the end of the year & 0.896 \\
\hline
\end{tabular}

Smart humanities

0.898

and science

Smart ICT system

0.803

X7: Education expenditure per capita

$\mathrm{X} 8$ : The proportion of the population with higher education over the age of 25

X9: The proportion of employees in the ICT industry in the whole society

0.899

0.923

0.870

0.746

0.862

$\mathrm{X} 11$ : Number of inhouse fiber optic networks

0.803

X12: Quantity of express delivery

0.772

0.598

X14: Green coverage in built-up areas

0.791

management

$0.721 \quad \mathrm{X} 13$ : Treatment rate of domestic sewage

X15: The area of parks

Note: The distinguishing coefficient is valued to 0.5 . 


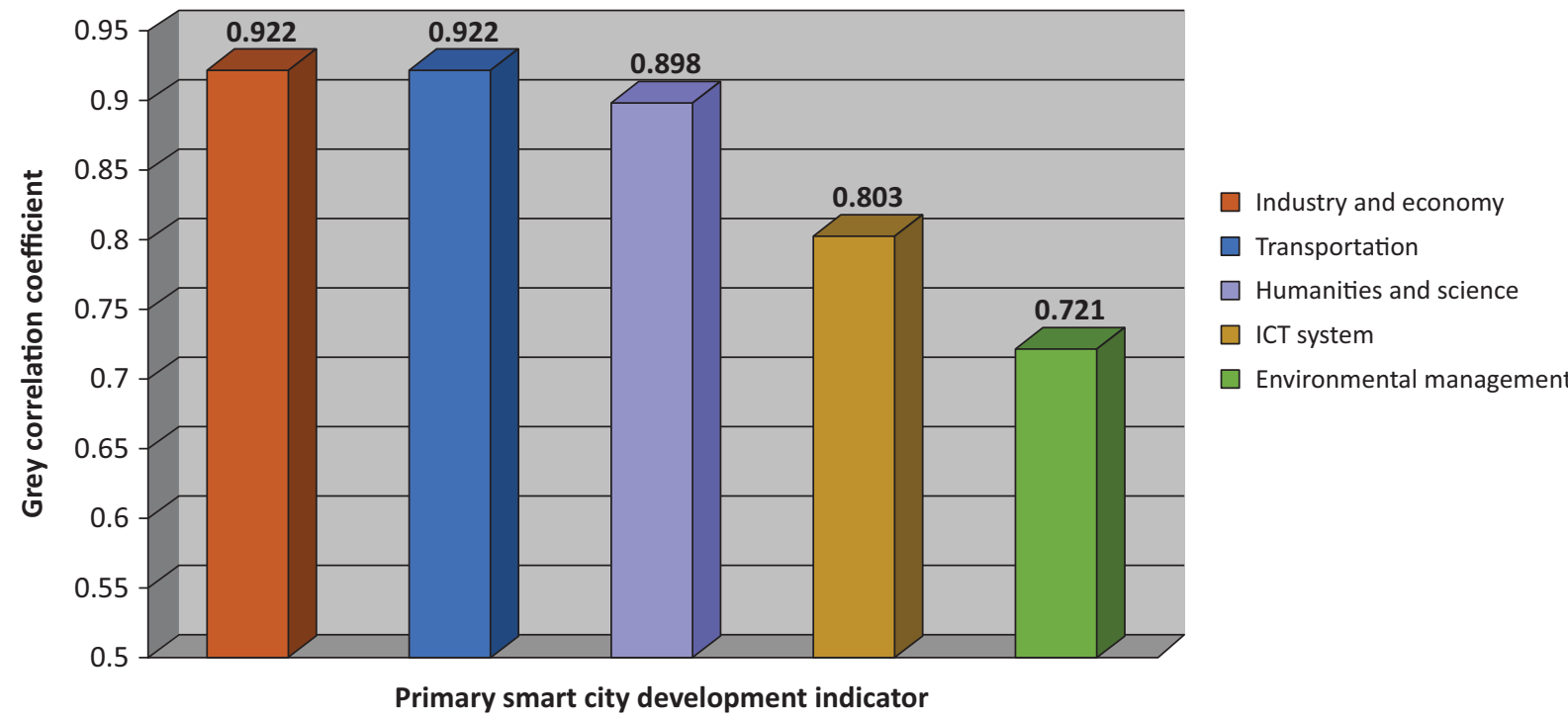

Figure 3. Grey correlation degree of primary indicators of smart city development.

a scientific development of urban transportation space. Throughout the past decade, the expansion and renovation of urban roads has been ongoing in Nanjing; as a direct consequence, the total urban road area has been growing rapidly and consistently. On the other hand, the rapid growth of bus and rail transit services also mirrors the improvement of the utilization of urban road resources alongside the establishment of the urban smart transportation system. This has greatly accelerated the internal population mobility and mitigated road congestion within the urban area, and indirectly improved the extent of urban land use, laying a solid foundation for a benign expansion of urban land.

For the indicator smart humanities and science, the correlation is 0.898 , ranking third of the primary indicators. More specifically, the correlation value between the proportion of highly educated people and the change of urban land use is as high as 0.923 , suggesting that highly educated residents can produce a higher value for urban construction and development. The indicator of per capita education expenditure, as an important symbol of educated population, implies the level of educational consumption in the target area and reflects the public's degree of acceptance, perception, acquisition, and application of scientific knowledge. However, the correlation of this indicator is lower than that of the proportion of highly educated people, which is probably because the education system has a long output circle and its direct contribution to the social value is limited in the short term. But in the long term, the continuous growth of per capita education expenditure is conducive to the cultivation of an educated population. The indicator of people engaged in ICT services demonstrates the human resources status of the information industry to a certain extent, and indirectly reflects the development of urban information technology. The improvement in the productivity and attractiveness of urban land will consequently promote the change in urban land utilization.
The correlation between smart ICT system and urban expansion is 0.803 , lower than the indicators mentioned above, but it also drives urban expansion to some degree. Among its secondary indicators, the number of Internet access users represents the level of urban Internet construction, which is a key and typical indicator for the construction of smart infrastructure and therefore has the highest correlation with urban expansion (0.862). This indicator reflects the popularity and digitalization of the urban network, not only accelerating the flow of effective urban information but also increasing the attraction of a smart city to the people from its surrounding regions. Similarly, the increase in the number of express deliveries indicates the continuous expansion of the express industry, the improvement of urban logistics system, the enhancement of livelihood service ability, and the increase of information intelligence. However, with the effect of the traditional business model transforming from offline to online under the impact of information technology, the development of the tertiary industry has experienced an exponential growth in recent years, and thus, its synergic development with urban land expansion has been highly affected. The number of mobile phone users reflects the popularity of urban communication facilities; as an interactive carrier of information space, communication facilities have become the hardware infrastructure for people to directly access to smart city services and management. But because mobile phones had been popularized in Nanjing as early as in 2008 , the growth of mobile phone users in recent years may only imply the increase in urban population. Moreover, in view of the common phenomenon that one user may have multiple phones and numbers, the actual reference value of this indicator is much reduced (only 0.746 ).

The correlation between smart environment management and urban expansion is the lowest out of the primary indicators (0.721). Specifically, both the area of parks and the green coverage rate of the built-up re- 
gion can reflect the environmental attractiveness of a city and the quality of urban living environment, but the correlation value differs greatly between the two $(0.791$ and 0.598 respectively). The construction of green infrastructure is often started after the completion of the municipal grey infrastructure, which means it usually occurs after the corresponding urban land expansion phenomenon, and therefore exhibits a delay and an insignificant driving effect. On the contrary, the area of park is more consistent with the trend of urban land expansion, suggesting that people's demand for green ecological services is on the rise together with the development of the city. Finally, the correlation between the urban sewage treatment rate and urban land expansion is 0.791 . Although this indicator shows an overall increasing trend year by year, due to the bottleneck encountered after the renovation of scientific and technological means or services, the sewage treatment rate has been gradually approaching to $100 \%$ and its relevance with urban expansion may decline in the future.

To sum up, we observed that there is a strong correlation between many of the chosen "smart" city development indicators and urban growth in Nanjing, particularly the indicators in the industry and economy, transportation, and humanities and science categories. Although these primary indicators are traditional land expansion drivers, we observe that the secondary "smart" indicators affected by ICT are still close to the grey correlation value found for the traditional indicators. This further confirms that the traditional urban land use change factors affected by ICT, even if defined as "smart" drivers, still have an influence on urban land expansion.

\section{Conclusion}

This study investigates the impact of ICT expansion on urban growth by means of the GRA method. The case study of Nanjing's smart city development has elucidated the ICT influence on regional economic, political, cultural, social, and evolving urban spatial structure. We believe that this research approach used from the qualitative analysis of traditional land use driving factors to the quantitative exploration or grey scale correlation, can be applied to other cities as well. Based on our analysis, we summarize the following main points:

- GRA is an effective and convenient method, especially in view of ambiguous definitions of indicators, difficulty in data collection and lack of relevant information. Although GRA is a traditional data analysis method, to our best knowledge it here used for the first time to quantify the correlation between driving forces and land expansion;

- From the significant changes in various indicators, it is apparent that the smart city construction in Nanjing has happened at a rapid rate from 2008 to 2018. The relatively high correlation between the smart city development indicators and urban land expansion further show that most of the smart city construction strategies in Nanjing have more or less driven urban land expansion. Therefore, it is suggested that the top layer design of urban land planning needs to be better optimized with respect to various indicators to achieve a more efficient use of resources;

- Prioritizing the industrial economy and transportation has been a win-win approach for simultaneously achieving urbanization and "smartness" in the city of Nanjing. However, indicators with a weaker effect on urban expansion, such as humanities and science, information system, and environmental management should also be accounted for, as they have all played essential roles in improving urban land utilization and enhancing people's quality of life.

In general, urban planners and decision-makers should understand the priorities of smart city development indicators at all stages of urban development, so as to properly adjust and respond to urban land expansion and help better coordinate land use planning in the future. Urban growth is a complex process involving the interaction of many factors, therefore there is no single model that can prove its direct driving causality, especially in view of the limited information that is generally available. The GRA method considers the changes in multiple variables and establishes a grey correlation among the "smart" driving factors and urban built-up land area, however correlation does not imply a simple causal relationship that explains the driving effect.

More research should therefore focus on causality. To this end, we first need to explore more effective "smart" drivers as comprehensively as is possible with the available data. Furthermore, we need to explore the future development of cities from different perspectives and on different scales, by including more land use indicators in the reference sequence, such as the urban land use degree and intensity. Finally, we can combine the "smart" drivers with the traditional urban land use change drivers to jointly establish optimized regression models for monitoring and simulating future land use change.

\section{Acknowledgments}

We acknowledge Dr. Haozhi Pan for his early guidance and suggestions on the topic of this article. We are thankful for the data support from China's National Administrative Division Information Platform (http://xzqh.mca.gov.cn) and the Ministry of Housing and Urban-Rural Development of the People's Republic of China (http://www.mohurd.gov.cn).

\section{Conflict of Interests}

The authors declare no conflict of interests. 


\section{Supplementary Material}

Supplementary material for this article is available online in the format provided by the authors (unedited).

\section{References}

Albino, V., Berardi, U., \& Dangelico, R. M. (2015). Smart cities: Definitions, dimensions, performance, and initiatives. Journal of Urban Technology, 22(1), 3-21.

Allwinkle, S., \& Cruickshank, P. (2011). Creating smarter cities: An overview. Journal of Urban Technology, 18(2), 1-16.

Anthopoulos, L. G., \& Vakali, A. (2012). Urban planning and smart cities: Interrelations and reciprocities. In $\mathrm{F}$. Álvarez, F. Cleary, P. Daras, J. Domingue, A. Galis, A. Garcia, ... T. Zahariadis (Eds.), The future internetFuture internet assembly 2012: From promises to reality (pp. 178-189). Berlin: Springer.

Batty, M., Axhausen, K. W., Giannotti, F., Pozdnoukhov, A., Bazzani, A., Wachowicz, M., ... Portugali, Y. (2012). Smart cities of the future. The European Physical Journal Special Topics, 214(1), 481-518.

Bibri, S. E., \& Krogstie, J. K. (2017). ICT of the new wave of computing for sustainable urban forms: Their big data and context-aware augmented typologies and design concepts. Sustainable Cities and Society, 32, 449-474.

Braimoh, A. K., \& Onishi, T. (2007). Spatial determinants of urban land use change in Lagos, Nigeria. Land Use Policy, 24(2), 502-515.

Campbell, M. (2019). Learn RStudio IDE: Quick, effective, and productive data science. Berkeley, CA: Apress.

Chen, J., Chang, K., Karacsonyi, D., \& Zhang, X. (2014). Comparing urban land expansion and its driving factors in Shenzhen and Dongguan, China. Habitat International, 43, 61-71.

Chourabi, H., Taewoo, N., Walker, S., Gil-Garcia, J. R., Mellouli, S., Nahon, K., . . . Scholl, H. J. (2012). Understanding smart cities: An integrative framework. Paper presented at the 45th Hawaii International Conference on System Sciences, Maui, Hawaii, USA.

Cocchia, A. (2014). Smart and digital city: A systematic literature review. In R. Dameri \& C. Rosenthal-Sabroux (Eds.), Smart city (pp. 13-43). Cham: Springer.

Cohen-Blankshtain, G., \& Rotem-Mindali, O. (2016). Key research themes on ICT and sustainable urban mobility. International Journal of Sustainable Transportation, 10(1), 9-17.

Deng, J. L. (1982). Control problems of grey systems. Systems \& Control Letters, 1(5), 288-294.

Deng, J. L. (1989). Introduction to grey system theory. The Journal of Grey System, 1(1), 1-24.

Eggleston, K., Jensen, R., \& Zeckhauser, R. (2002). Information and communication technologies, markets and economic development. In G. S. Kirkman, P. K. Cornelius, J. D. Sachs, \& K. Schwab (Eds.), The global information technology report: Readiness for the net- worked world (pp. 62-75). New York, NY: Oxford University Press.

Ergazakis, K., Metaxiotis, K., \& Psarras, J. (2004). Towards knowledge cities: Conceptual analysis and success stories. Journal of Knowledge Management, 8(5), 5-15.

Firmino, R. J. (2005). Planning the unplannable: How local authorities integrate urban and ICT policy making. Journal of Urban Technology, 12(2), 49-69.

Giffinger, R., Fertner, C., Kramar, H., \& Meijers, E. (2007). City-ranking of European medium-sized cities. Vienna: Centre of Regional Science.

Graham, S. (2002). Bridging urban digital divides? Urban polarization and information and communication technologies (ICTs). Urban Studies, 39(1), 33-56.

Han, J., Hayashi, Y., Cao, X., \& Imura, H. (2009). Evaluating land-use change in rapidly urbanizing China: Case study of Shanghai. Journal of Urban Planning and Development, 135(4), 166-171.

Hernández-Muñoz, J. M., Vercher, J. B., Muñoz, L., Galache, J. A., Presser, M., Gómez, L. A. H., \& Pettersson, J. (2011). Smart cities at the forefront of the future internet. In J. Domingue, A. Galis, A. Gavras, T. Zahariadis, D. Lambert, F. Cleary, . . . S. Nilsson (Eds.), The future internet-Future internet assembly 2011: Achievements and technological promises (pp. 447-462) Berlin: Springer.

Hu, A., Yan, Y., \& Wang, Y. (2010). Major development goals and indicators for China's 12th five-year plan. Journal of Tsinghua University (Philosophy and Social Sciences), 1, 12.

Karvonen, A., Cugurullo, F., \& Caprotti, F. (2018). Inside smart cities: Place, politics and urban innovation. London: Routledge.

Kuo, Y., Yang, T., \& Huang, G. W. (2008). The use of grey relational analysis in solving multiple attribute decision-making problems. Computers \& Industrial Engineering, 55(1), 80-93.

Lambin, E. F., Turner, B. L., Geist, H. J., Agbola, S. B., Angelsen, A., Bruce, J. W., . . . Xu, J. (2001). The causes of land-use and land-cover change: Moving beyond the myths. Global Environmental Change, 11(4), 261-269.

Lea, R. (2017). Smart cities: An overview of the technology trends driving smart cities. IEEE, 3, 1-16.

Li, X., Zhou, W., \& Ouyang, Z. (2013). Forty years of urban expansion in Beijing: What is the relative importance of physical, socioeconomic, and neighborhood factors? Applied Geography, 38, 1-10.

Lombardi, P., Giordano, S., Farouh, H., \& Yousef, W. (2012). Modelling the smart city performance. Innovation: The European Journal of Social Science Research, 25(2), 137-149.

Loo, B. P. Y., \& Wang, B. (2017). Progress of edevelopment in China since 1998. Telecommunications Policy, 41(9), 731-742.

Maeng, D. M., \& Nedovic-Budic, Z. (2007). Chicago and Seoul: A comparative study of the impact of infor- 
mation and communications technologies on urban land use and regulation. Journal of Urban Technology, 11(2), 61-92.

Maeng, D. M., \& Nedovic-Budic, Z. (2010). Relationship between ICT and urban form in knowledge-based development: Empirical analysis of Washington, DC metro region. International Journal of KnowledgeBased Development, 1(1/2), 97-117.

Makushkin, S. A., Kirillov, A. V., Novikov, V. S., Shaizhanov, M. K., \& Seidina, M. Z. (2016). Role of inclusion "smart city" concept as a factor in improving the socio-economic performance of the territory. International Journal of Economics and Financial Issues, 6(1), 152-156.

Mokhtarian, P. L., \& Tal, G. (2013). Impacts of ICT on travel behavior: A tapestry of relationships. In J. P. Rodrigue, T. Nottemboom, \& J. Shaw (Eds.), The SAGE handbook of transport studies (pp. 241-260). Washington, DC: SAGE.

Neirotti, P., de Marco, A., Cagliano, A. C., Mangano, G., \& Scorrano, F. (2014). Current trends in smart city initiatives: Some stylised facts. Cities, 38, 25-36.

Parcerisas, L., Marull, J., Pino, J., Tello, E., Coll, F., \& Basnou, C. (2012). Land use changes, landscape ecol- ogy and their socioeconomic driving forces in the Spanish Mediterranean coast (El Maresme County, 1850-2005). Environmental Science \& Policy, 23, 120-132.

Platt, R. H. (2004). Land use and society, revised edition: Geography, law, and public policy. Washington, DC: Island Press.

Serra, P., Pons, X., \& Saurí, D. (2008). Land-cover and land-use change in a Mediterranean landscape: $A$ spatial analysis of driving forces integrating biophysical and human factors. Applied Geography, 28(3), 189-209.

Tan-Mullins, M., Cheshmehzangi, A., Chien, S., \& Xie, L. (2017). Smart-eco cities in China: Trends and city profiles 2016. Exeter: University of Exeter.

Wang, Y., \& Zhang, X. (2001). Adynamic modeling approach to simulating socioeconomic effects on landscape changes. Ecological Modelling, 140(1/2), 141-162.

Yang, F., Zeng, G., Du, C., Tang, L., Zhou, J., \& Li, Z. (2008). Spatial analyzing system for urban land-use management based on GIS and multi-criteria assessment modeling. Progress in Natural Science, 18(10), 1279-1284.

\section{About the Authors}

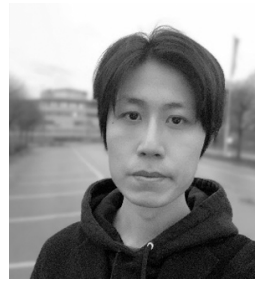

Zipan Cai is a PhD student in the Department of Sustainable Development, Environmental Science and Engineering (SEED) at the KTH Royal Institute of Technology, Sweden. His research interests include urban spatial planning, spatial dynamic modeling, planning support system, and smart city studies. He has over 9 years of experience in the field of GIS and related professional skills. His current research focuses on decision support for urban planning.

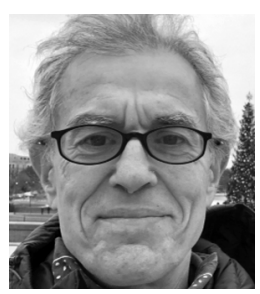

Vladimir Cvetkovic (PhD) is a Full Professor in water system engineering at the Department of Sustainable Development, Environmental Science and Engineering (SEED) at the KTH Royal Institute of Technology, Sweden. His research has been mostly focused on water resources involving theoretical and experimental studies. Since 2015 , he has been coordinating and working on projects related to urban systems in particular the socio-technical development toward sustainable smart cities.

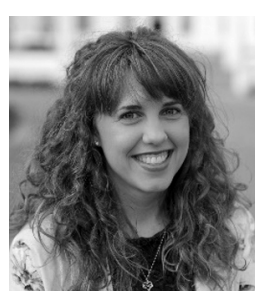

Jessica Page is a PhD student at Department of Physical Geography, Stockholm University, Sweden. Her focus is on urban and regional planning, in particular on using technology and planning support systems to further sustainability goals in cities through the study and modelling of the interactions between urban and sub-urban social systems with various ecological systems, ecosystem services and water-climate interactions. 